\title{
Investigation of a Counter Flow Microchannel Heat Exchanger Performance with Using Nanofluid as a Coolant
}

\author{
Mushtaq I. Hasan ${ }^{1}$, Abdul Muhsin A. Rageb ${ }^{2}$, Mahmmod Yaghoubi ${ }^{3}$ \\ ${ }^{1}$ Department of Mechanical Engineering, College of Engineering, Thi-Qar University, Nasiriyah, Iraq \\ ${ }^{2}$ Department of Mechanical Engineering, College of Engineering, Basra University, Basra, Iraq \\ ${ }^{3}$ Academy of Sciences of Iran, Tehran, Iran \\ Email: mushtaq76h@yahoo.com
}

Received December 18, 2011; revised February 24, 2012; accepted March 12, 2012

\begin{abstract}
In this paper the performance of a counter flow microchannel heat exchanger (CFMCHE) is numerically investigated with a nanofluid as a cooling medium. Two types of nanofluids are used $\mathrm{Cu}$-water and $\mathrm{Al}_{2} \mathrm{O}_{3}$-water. From the results obtained it's found that thermal performance of CFMCHE increased with using the nanofluids as cooling medium with no extra increase in pressure drop due to the ultra fine solid particles and low volume fraction concentrations. The nanofluids $\left(\mathrm{Cu}\right.$-water and $\mathrm{Al}_{2} \mathrm{O}_{3}$-water) volume fractions were in the range $1 \%$ to $5 \%$. It's also found that nanofluid-cooled CFMCHE could absorb more heat than water-cooled CFMCHE when the flow rate was low. For high flow rates the heat transfer was dominated by the volume flow rate and nanoparticles did not contribute to the extra heat absorption. Also the performance of CFMCHE can be increased considerably by using nanofluids with higher thermal conductivities.
\end{abstract}

Keywords: Nanofluids; Microchannel Heat Exchanger; Effectiveness; Laminar Flow; Numerical Simulation

\section{Introduction}

One of the methods for enhancing heat transfer is the application of additives to the working fluid. The basic idea is to enhance heat transfer by changing the fluid transport properties such as in nanofluid where the solid particles added to the base fluid to increase its thermal conductivity. Nanofluid consists of a base fluid such as water and nano scale metallic or non-metallic particles. The term of nanofluids was first used by the group at the Argonne National Laboratory, USA, about a decade ago. Then using a nanofluids as a heat transfer working fluid has gained much attention in recent years due to its potential advantages include higher thermal conductivity than the pure fluids, excellent stability and little increase in pressure drop.

Tuckerman and Pease [1] introduced the idea of using microchannel heat sink (MCHS) for cooling of electronic devices in 1981. They experimentally demonstrated the MCHS capability and claimed that they were able to dissipate heat flux rate of $790 \mathrm{~W} / \mathrm{cm}^{2}$. They showed that the convective heat transfer of single phase flows could be improved by decreasing the width of the heat sink channels and by increasing the area wetted by the heat transfer fluid. The experimental and analytical studies by Wang et al. [2], Lee et al. [3], Wang et al. [4] and Koo and Kleinstreuer [5] showed that nanofluids have higher thermal conductivity than pure fluids and therefore it has great potential for heat transfer enhancement.

Li and Xuan [6], Xuan and Li [7] and Pak and Cho [8] experimentally measured the convection heat transfer and pressure drop for nanofluid tube flows. Their results indicated that heat transfer coefficient was greatly enhanced and depends on the Reynolds number, the particle size and shape, and particle volume fraction. They also found that nano particles did not cause an extra pressure drop.

Donsheng and Yulog [9] studied experimentally the convective heat transfer of nanofluid made of $\gamma-\mathrm{Al}_{2} \mathrm{O}_{3}$ water, flowing through a copper tube in the laminar flow regime. They showed a considerable enhancement of convective heat transfer using the nanofluids. The enhancement was particularly significant in the entrance region, and was much higher than that solely due to the enhancement on thermal conduction.

Seok and Choi [10] investigated numerically the cooling performance of microchannel heat sink with nanofluids. They showed that the cooling performance of a MCHS with water based nanofluids containing diamond $(1 \%$ volume fraction and $2 \mathrm{~nm}$ ) at the fixed pumping power of $2.25 \mathrm{~W}$ is enhanced by about $10 \%$ compared with that of a MCHS with water.

Tsung and Reigu [11] studied analytically the performance of microchannel heat sink (MCHS) using copper-water $\left(\mathrm{Cu}-\mathrm{H}_{2} \mathrm{O}\right)$ and carbon nanotube-water (CNT$\mathrm{H}_{2} \mathrm{O}$ ) nanofluids as coolants. Velocity and temperature 
distributions were obtained by modeling the MCHS as a porous media. The resulting velocity and temperature were then used to evaluate the thermal resistance that characterizes MCHS performance. They found that the nanofluid reduces the temperature difference between the MCHS bottom wall and bulk nanofluid compared with that from pure fluid, which lead to produces a reduction in conductive thermal resistance.

Joescon and Issam [12] performed experiments to explore the microchannel cooling benefits of $\mathrm{Al}_{2} \mathrm{O}_{3}$-water nanofluid. They found that the high thermal conductivity of nano particles enhance the single phase heat transfer coefficient especially for laminar flow. Higher heat transfer coefficient was achieved mostly in the entrance region of the microchannels and the enhancement was weaker in the fully developed region, providing that nano particles have an appreciable effect on thermal boundary layer development. It was also observed that higher concentrations also produced greater sensitivity to heat flux.

Mushtaq et al. [13] investigated numerically the effect of channels geometry (the size and shape of channels) on the performance of counter flow microchannel heat exchanger and used liquid water as a cooling fluid. They found that with decreasing the size of channels both the effectiveness of heat exchanger and pressure drop were increased and they claimed that the decision of increaseing or decreasing the size of channels depends on the application in which this heat exchanger is used. Also they found that the circle is the best shape for the channels of this type of heat exchangers since it gives higher overall performance (including both the hydrodynamic and thermal performance).

Mushtaq I. Hasan [14] numerically investigated the performance of counter flow microchannel heat exchanger with MEPCM suspension as a cooling fluid. He fund that, using of MEPCM suspension lead to improve thermal performance of CFMCHE but it also lead to extra increase in pressure drop and as results the overall performance decreased with using this suspension as a cooling medium.

Most of the studies made to investigate heat transfer and flow characteristics of nanofluids were carried out in macro-scale dimensions. Only a few studies addressed the nanofluid flow and heat transfer in micro-scale dimensions [11]. In this paper an investigation is made to study the effect of using nanofluids as a cooling medium on the performance of CFMCHE.

\section{Mathematical Model}

For modeling, nanofluid is treated as a single-phase fluid. This assumption can be applicable since the particles are ultra fine and they are easily fluidized [6,7]. Moreover, the particle volume fraction in nanofluid is usually low. Under such assumptions the governing equations for the nanofluid flow and heat transfer are greatly simplified and local fluid and particles are in thermal equilibrium.

Schematic structure of the studied counter flow microchannel heat exchanger with square channels is shown in Figure 1. To study the entire CFMCHE numerically it is complicated and needs huge of CPU time. Therefore and due to the geometrical and thermal symmetry between hot and cold channels rows, an individual heat exchange unit which consists of two channels containing hot and cold fluids and a separating wall is considered as shown in Figure 2 will be used as a model to represent the complete counter flow microchannel heat exchanger since it give an adequate indication about its performance and the heat is transferred from hot fluid to cold fluid through the thick wall separating them.

The governing equations for 3D, laminar, steady and incompressible with constant fluid properties are:

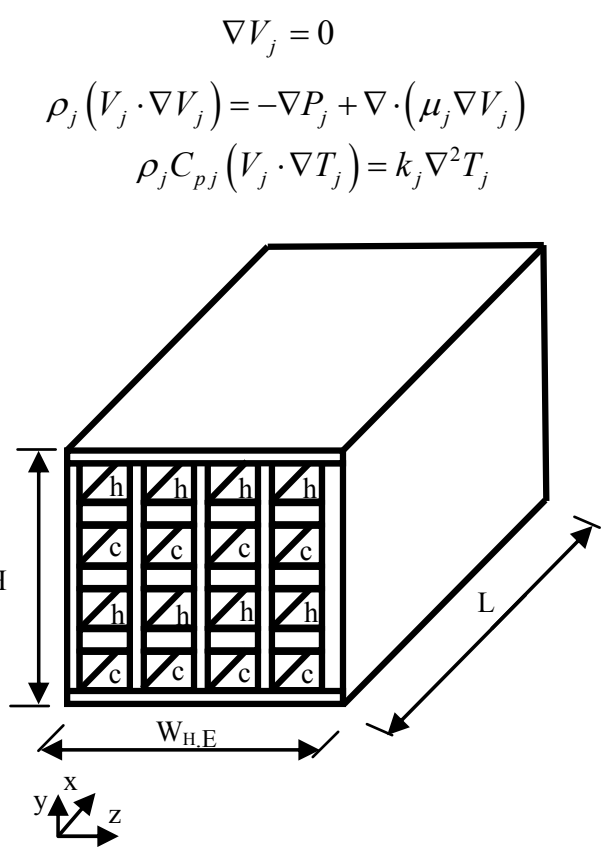

Figure 1. A schematic model of the counter flow MCHE.

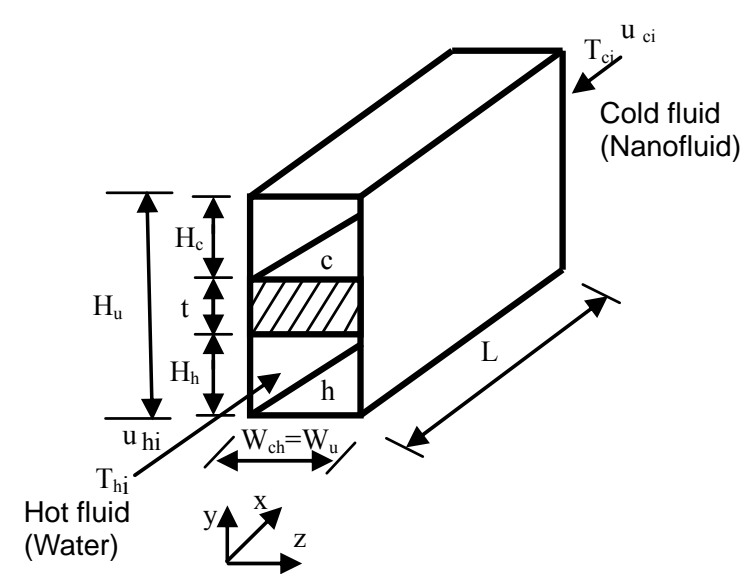

Figure 2. A schematic of heat exchange unit. 
For solid

$$
k_{s} \nabla^{2} T_{s}=0
$$

where $\mathrm{j}=\mathrm{h}$ and $\mathrm{c}$ for hot and cold channels respectively.

The boundary conditions used are:

For lower channels (hot fluid) (water) $(0 \leq \mathrm{y} \leq \mathrm{Hh})$

\begin{tabular}{|c|c|c|}
\hline Location & B.C & Comments \\
\hline$x=0$ & $\mathrm{uh}=\mathrm{uhi}, \mathrm{vh}=\mathrm{wh}=0 \mathrm{Th}=\mathrm{Thi}$ & Hot fluid inflow \\
\hline$x=\mathrm{L}$ & $\begin{array}{c}\frac{\partial u_{h}}{\partial x}=v_{h}=w_{h}=0 \\
\frac{\partial T_{h}}{\partial x}=0\end{array}$ & $\begin{array}{l}\text { Hot fluid outflow } \\
\text { (fully developed flow, } \\
\text { end of channel) }\end{array}$ \\
\hline $\mathrm{z}=0$ & $\begin{array}{c}\mathrm{uh}=\mathrm{vh}=\mathrm{wh}=0 \\
\frac{\partial T_{h}}{\partial x}=0\end{array}$ & No-slip, adiabatic wall \\
\hline $\mathrm{z}=\mathrm{Wch}$ & $\begin{array}{c}\mathrm{uh}=\mathrm{vh}=\mathrm{wh}=0 \\
\frac{\partial T_{h}}{\partial x}=0\end{array}$ & No-slip, adiabatic wall \\
\hline$y=0$ & $\begin{array}{c}\mathrm{uh}=\mathrm{vh}=\mathrm{wh}=0 \\
\frac{\partial T_{h}}{\partial x}=0\end{array}$ & No-slip, adiabatic wall \\
\hline$y=H h$ & $\begin{aligned} \mathrm{uh}=\mathrm{vh} & =\mathrm{wh}=0 \\
-k_{h} \frac{\partial T_{h}}{\partial y} & =-k_{s} \frac{\partial T_{s}}{\partial y} \\
\mathrm{Th} & =\mathrm{Ts}\end{aligned}$ & $\begin{array}{l}\text { Fluid-solid interface } \\
\text { (no-slip, conjugate heat } \\
\text { transfer) }\end{array}$ \\
\hline
\end{tabular}

For upper channel (cold fluid) (Nanofluid) $(\mathrm{Hh}+\mathrm{t} \leq \mathrm{y}$ $\leq \mathrm{Hh}+\mathrm{t}+\mathrm{Hc})$

\begin{tabular}{|c|c|c|}
\hline Location & B.C & Comments \\
\hline$x=0$ & $\begin{array}{c}\frac{\partial u_{c}}{\partial x}=v_{c}=w_{c}=0 \\
\frac{\partial T_{c}}{\partial x}=0\end{array}$ & $\begin{array}{l}\text { Cold fluid outflow (fully } \\
\text { developed flow, end of } \\
\text { channel }\end{array}$ \\
\hline$x=\mathrm{L}$ & $\begin{array}{c}\mathrm{uc}=\mathrm{uci}, \mathrm{vc}=\mathrm{wc}=0 \\
\mathrm{Tc}=\mathrm{Tci} \\
\mathrm{uc}=\mathrm{vc}=\mathrm{wc}=0\end{array}$ & Cold fluid inflow \\
\hline$z=0$ & $\begin{array}{c}\frac{\partial T_{c}}{\partial z}=0 \\
\mathrm{uc}=\mathrm{vc}=\mathrm{wc}=0\end{array}$ & No-slip, adiabatic wall \\
\hline $\mathrm{z}=\mathrm{Wch}$ & $\frac{\partial T_{c}}{\partial z}=0$ & No-slip, adiabatic wall \\
\hline$y=H h+t$ & $\begin{aligned} \mathrm{uc}=\mathrm{vc} & =\mathrm{wc}=0 \\
-k_{c} \frac{\partial T_{c}}{\partial y} & =-k_{s} \frac{\partial T_{s}}{\partial y} \\
\mathrm{Tc} & =\mathrm{Ts}\end{aligned}$ & $\begin{array}{l}\text { Fluid-solid interface } \\
\text { (no-slip, conjugate heat } \\
\text { transfer) }\end{array}$ \\
\hline$y=H h+t H c$ & $\begin{array}{c}\mathrm{uc}=\mathrm{vc}=\mathrm{wc}=0 \\
\frac{\partial T_{c}}{\partial y}=0\end{array}$ & no-slip, adiabatic wall \\
\hline
\end{tabular}

For solid wall separating two channels $(\mathrm{Hh} \leq \mathrm{y} \leq \mathrm{Hh}+$ t)

\begin{tabular}{|c|c|c|}
\hline Location & B.C & Comments \\
\hline$x=0$ & $\frac{\partial T_{s}}{\partial x}=0$ & Adiabatic wall \\
\hline$x=\mathrm{L}$ & $\frac{\partial T_{s}}{\partial x}=0$ & Adiabatic wall \\
\hline$z=0$ & $\frac{\partial T_{s}}{\partial z}=0$ & Adiabatic wall \\
\hline $\mathrm{z}=\mathrm{Wch}$ & $\frac{\partial T_{s}}{\partial z}=0$ & Adiabatic wall \\
\hline$y=H h$ & $\begin{aligned}-k_{h} \frac{\partial T_{h}}{\partial y} & =-k_{s} \frac{\partial T_{s}}{\partial y} \\
\mathrm{Th} & =\mathrm{Ts}\end{aligned}$ & Fluid-solid interface \\
\hline$y=H h+t$ & $\begin{aligned}-k_{c} \frac{\partial T_{c}}{\partial y} & =-k_{s} \frac{\partial T_{s}}{\partial y} \\
\mathrm{Tc} & =\mathrm{Ts}\end{aligned}$ & Fluid-solid interface \\
\hline
\end{tabular}

By solving the above governing equations the distribution of velocity, pressure and temperature are determined in the fluids and solid domains. From these distributions the other parameters such as effectiveness, heat transfer rate, pressure drop, pumping power required and overall performance index are determined.

Heat exchanger effectiveness is the ratio of the actual heat transfer to the maximum possible heat that can be transferred:

$$
\varepsilon=\frac{q}{q_{\max }}
$$

where

$$
q_{\max }=C_{\min }\left(T_{h i}-T_{c i}\right)
$$

and

where

$$
q=C_{h}\left(T_{h i}-T_{h o}\right)=C_{c}\left(T_{c o}-T_{c i}\right)
$$

$$
C_{h}=\dot{m} C p_{h}
$$

and

$$
\begin{gathered}
C_{c}=\dot{m} C p_{c} \\
\varepsilon=\frac{C_{h}\left(T_{h i}-T_{h o}\right)}{C_{\min }\left(T_{h i}-T_{c i}\right)}=\frac{C_{c}\left(T_{c o}-T_{c i}\right)}{C_{\min }\left(T_{h i}-T_{c i}\right)}
\end{gathered}
$$

The pumping power required to circulate the hot and cold fluids in CFMCHE is:

$$
P P=\dot{V} \Delta P t
$$

where $\dot{V}$ is the volumetric flow rate $\left(\mathrm{m}^{3} / \mathrm{s}\right)$ and $\Delta \mathrm{Pt}$ is total pressure drop in heat exchange unit.

$$
\begin{gathered}
\dot{V}=v_{i n} A \\
\Delta P_{t}=\Delta P_{h}+\Delta P_{c}=\left(P_{h i}-P_{h o}\right)+\left(P_{c i}-P_{c o}\right)
\end{gathered}
$$

To calculate the overall performance of the CFMCHE taking into consideration both thermal and hydrodynamic performances, the so called performance index is used 
which is the ratio of CFMCHE effectiveness to the total pressure drop is used [13]:

$$
\eta=\frac{\varepsilon}{\Delta P t}
$$

Other factor used to calculate the overall performance and to verify the results of performance index which is defined as the ratio of heat transfer rate to the pumping power required $\left(\frac{q(W)}{P P(W)}\right)[13,14]$.

\section{Properties of Nanofluids}

The thermo physical properties of the nanofluids are mainly depend upon the properties of the base fluid and the solid particles, volume fraction of the solid particles in the suspension and particles shape. The properties of nanofluids can be calculated using the following relations $[11,12]$ :

Thermal conductivity:

$$
k_{n f}=k_{f}\left[\frac{k_{p}+(S H-1) k_{f}-(S H-1) c\left(k_{f}-k_{p}\right)}{k_{p}+(S H-1) k_{f}+c\left(k_{f}-k_{p}\right)}\right]
$$

Viscosity:

$$
\mu_{n f}=\mu_{f}(1+2.5 c)
$$

Density:

$$
\rho_{n f}=c \rho_{p}+(1-c) \rho_{f}
$$

Specific heat:

$$
C p_{n f}=c C p_{p}+(1-c) C p_{f}
$$

where $\mathrm{SH}$ is solid particle shape factor.

$$
S H=\frac{3}{\psi}
$$

$\psi$ is sphericity defined as the ratio of the surface area of a sphere with a volume equal to that of the particle to the surface area of the particle. For spherical particles $S H=3$.

$k_{f}, k_{n f}, k_{p}$ are thermal conductivities of the base fluid, nanofluid and solid particles respectively.

In this paper two nanofluids were used. Water is the base fluid used for both of them and the solid particles are cupper $(\mathrm{Cu})$ for the first nanofluid and Aluminum oxide $\left(\mathrm{Al}_{2} \mathrm{O}_{3}\right)$ for the second. So the two nanofluids used are $\left(\mathrm{Cu}\right.$-water) and $\left(\mathrm{Al}_{2} \mathrm{O}_{3}\right.$-water $)$ and the volume fraction used are $(1 \%, 2 \%, 3 \%, 4 \%, 5 \%)$. The relation for viscosity, equation (13) is used up to $c=5 \%$ [11].

The properties of two nanofluids used (Cu-water) and $\left(\mathrm{Al}_{2} \mathrm{O}_{3}\right.$-water) are listed in Tables $\mathbf{1}$ and 2 [15].

\section{Numerical Solution}

A computational fluid dynamic code FLUENT 6.3 is

\begin{tabular}{|c|c|c|c|c|}
\hline Material & $\begin{array}{c}\rho \\
\mathrm{Kg} / \mathrm{m}^{3}\end{array}$ & $\begin{array}{c}C p \\
\mathrm{~J} / \mathrm{Kg} \cdot \mathrm{K}\end{array}$ & $\begin{array}{c}k \\
\mathrm{~W} / \mathrm{m} \cdot \mathrm{K}\end{array}$ & $\begin{array}{c}\mu \\
\mathrm{Kg} / \mathrm{m} \cdot \mathrm{s}\end{array}$ \\
\hline $\begin{array}{c}\text { Pure water } \\
c=0 \%\end{array}$ & 981.3 & 4189 & 0.643 & 0.000598 \\
\hline $\mathrm{Al}_{2} \mathrm{O}_{3}$ & 3600 & 765 & 36 & - \\
\hline $\begin{array}{c}\mathrm{Al}_{2} \mathrm{O}_{3} \text {-water } \\
c=1 \%\end{array}$ & 1007.4 & 4154.7 & 0.661 & 0.000612 \\
\hline $\begin{array}{c}\mathrm{Al}_{2} \mathrm{O}_{3} \text {-water } \\
c=2 \%\end{array}$ & 1033.6 & 4120.5 & 0.68 & 0.000627 \\
\hline $\begin{array}{c}\mathrm{Al}_{2} \mathrm{O}_{3} \text {-water } \\
c=3 \%\end{array}$ & 1059.8 & 4086.2 & 0.699 & 0.000642 \\
\hline $\begin{array}{c}\mathrm{Al}_{2} \mathrm{O}_{3} \text {-water } \\
\mathcal{C}=4 \%\end{array}$ & 1086 & 4052 & 0.719 & 0.000657 \\
\hline $\begin{array}{c}\mathrm{Al}_{2} \mathrm{O}_{3} \text {-water } \\
c=5 \%\end{array}$ & 1112.2 & 4017.8 & 0.739 & 0.000672 \\
\hline
\end{tabular}

Table 1. Thermo-physical properties of the (Cu-water) nanofluid.

\begin{tabular}{ccccc}
\hline Material & $\begin{array}{c}\rho \\
\mathrm{Kg} / \mathrm{m}^{3}\end{array}$ & $\begin{array}{c}C p \\
\mathrm{~J} / \mathrm{Kg} \cdot \mathrm{K}\end{array}$ & $\begin{array}{c}k \\
\mathrm{~W} / \mathrm{m} \cdot \mathrm{K}\end{array}$ & $\begin{array}{c}\mu \\
\mathrm{Kg} / \mathrm{m} \cdot \mathrm{s}\end{array}$ \\
\hline $\begin{array}{c}\text { Pure water } \\
c=0 \%\end{array}$ & 981.3 & 4189 & 0.643 & 0.000598 \\
$\begin{array}{c}\text { cupper }(\mathrm{Cu}) \\
\quad 8930\end{array}$ & 383.1 & 386 & - \\
$\begin{array}{c}\mathrm{Cu}-\text { water } \\
\quad=1 \%\end{array}$ & 1061 & 4150.9 & 0.662 & 0.000612 \\
$\begin{array}{c}\mathrm{Cu}-\text { water } \\
\quad=2 \%\end{array}$ & 1140.7 & 4112.8 & 0.682 & 0.000627 \\
$\begin{array}{c}\mathrm{Cu}-\mathrm{water} \\
\quad=3 \%\end{array}$ & 1220.4 & 4074.8 & 0.702 & 0.000642 \\
$\begin{array}{c}\mathrm{Cu}-\mathrm{water} \\
c=4 \%\end{array}$ & 1300.2 & 4036.7 & 0.723 & 0.000657 \\
$\begin{array}{c}\mathrm{Cu}-\mathrm{water} \\
c=5 \%\end{array}$ & 1378 & 3998 & 0.744 & 0.000672 \\
\hline
\end{tabular}

Table 2. Thermo-physical properties of the $\left(\mathrm{Al}_{2} \mathrm{O}_{3}\right.$-water $)$ nanofluid.

used to solve the governing equations and calculate the distributions of the flow velocity, pressure and temperature in a CFMCHE. For square channel with length $L=10$ mm, channel height $H=100 \mu \mathrm{m}$, width $W=100 \mu \mathrm{m}$, wall thickness $t=50 \mu \mathrm{m}$, the mesh used is hexahedral elements. For a flow of $\mathrm{Re}=50$, three mesh sizes were used. The first mesh set was $(16 \times 16 \times 90)$ and $(16 \times 8 \times$ $90)$ in $z, y, x$ directions for channels and wall respectively. The second mesh was $(20 \times 20 \times 110)$, and $(20 \times 10 \times$ $110)$ and the third mesh was $(25 \times 25 \times 110)$ and $(25 \times$ $15 \times 110$ ). The computational results for CFMCHE effectiveness and central velocity in fully developed region for meshes are listed in the Table 3 .

Table 3 shows that the solution becomes independent of grid size and from second configuration further increase in the grids will not have a significant effect on the solution and results of such arrangement are acceptable. Therefore and to gate maximum accuracy the grid size of $(25 \times 25 \times 110)$ and $(25 \times 15 \times 110)$ is used.

The convergence criteria to control the solution for momentum and energy equation were set to be less than $10^{-6}$. 
Table 3. Grid independent study.

\begin{tabular}{ccc}
\hline $\begin{array}{c}\text { Mesh } \\
\text { Configuration }\end{array}$ & $\begin{array}{c}\text { Effectiveness } \\
\%\end{array}$ & $\begin{array}{c}\text { Fully Developed Central } \\
\text { Velocity }(\mathrm{m} / \mathrm{s})\end{array}$ \\
\hline 1 & 42.81 & 0.6401 \\
2 & 42.26 & 0.6489 \\
3 & 42.22 & 0.6490 \\
\hline
\end{tabular}

\section{Results and Discussion}

First the model was solved with pure water as a cooling fluid with constant properties selected according to the mean temperature across channels $[16,17]$. The inlet temperatures of hot and cold fluids used as boundary conditions are $\mathrm{Thi}=373 \mathrm{~K}$ and $\mathrm{Tci}=293 \mathrm{~K}$.

To check the validity of the built numerical model, verification was made by solving the experimental model presented in [18] and results are compared. The experimental model presented in [18] is a microchannel heat sink consists of rectangular microchannels with hydraulic diameter $348.9 \mu \mathrm{m}$, channel height $713 \mu \mathrm{m}$, channel width $231 \mu \mathrm{m}$ and length $4.48 \mathrm{~cm}$. Temperature was measured in four points along the channel bottom wall, and experiment was made with inlet velocity of $1 \mathrm{~m} / \mathrm{s}$, inlet temperature of $288 \mathrm{~K}$ and thermal boundary condition is a constant heat flux of $100 \mathrm{~W} / \mathrm{cm}^{2}$ subjected on the bottom wall of the substrate.

Figure 3 shows the comparison between results of present numerical model and the experimental data of [18] for temperature distribution along the bottom wall of the channel. From this figure it can be seen that, the agreement between numerical and experimental results is acceptable since the maximum error is $1.41 \%$ which may be due to the end effect. Therefore the present numerical model is reliable and can be used to study the effect of using nanofluid as a coolant on the performance of a CFMCHE.

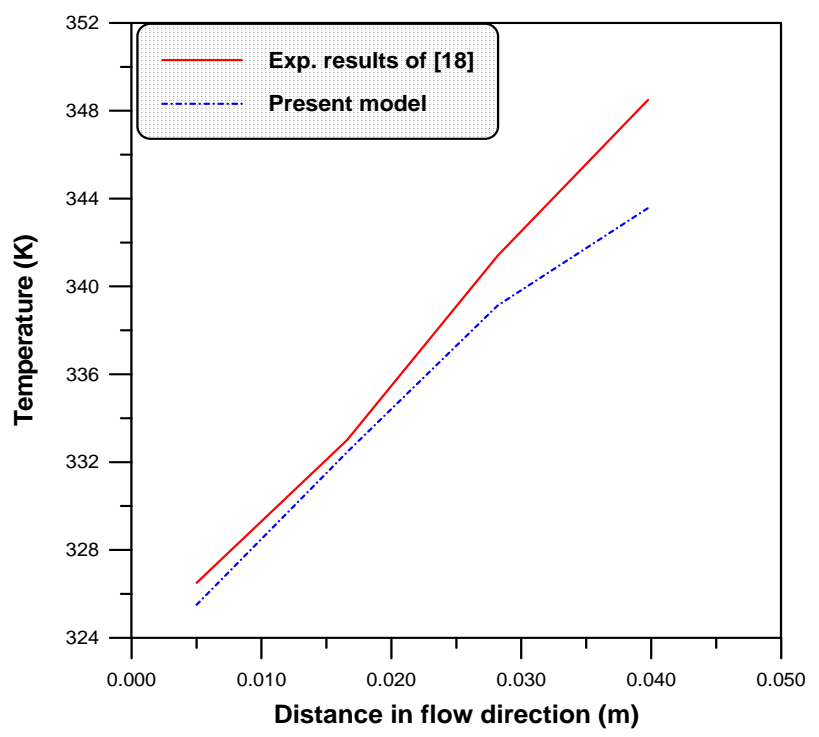

Figure 3. Variation of wall temperature in flow direction as a comparison between present model and [18].
Figure 4 shows the variation of thermal conductivity of nanofluid with particles volume fractions in the suspension. From this figure one can see that, thermal conductivity is increased with increasing volume fraction. Also it can be seen that the thermal conductivity of $\mathrm{Cu}$ water nanofluid is higher than the conductivity of $\mathrm{Al}_{2} \mathrm{O}_{3}$ water nanofluid because the conductivity of copper is larger.

Variation of nanofluid viscosity with the volume fraction is indicated in Figure 5. From this figure the viscosity increased with increase of the fraction of solid particles in the suspension.

Figure 6 shows the variation of heat exchanger effectiveness with volume fraction for two types of

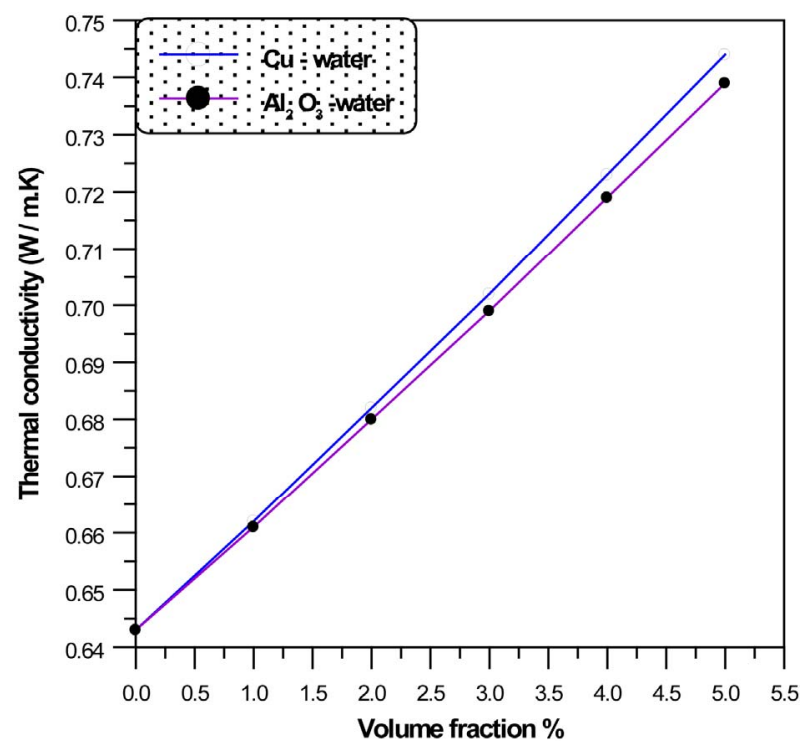

Figure 4. Variation of thermal conductivity with volume fraction for two types of nanofluids.

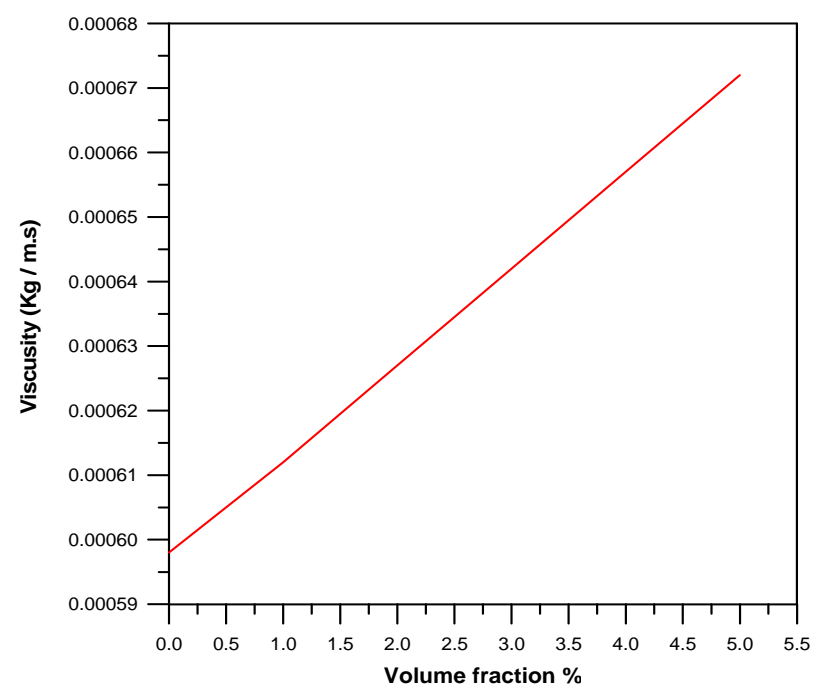

Figure 5. Variation of viscosity of nanofluid with volume fraction. 


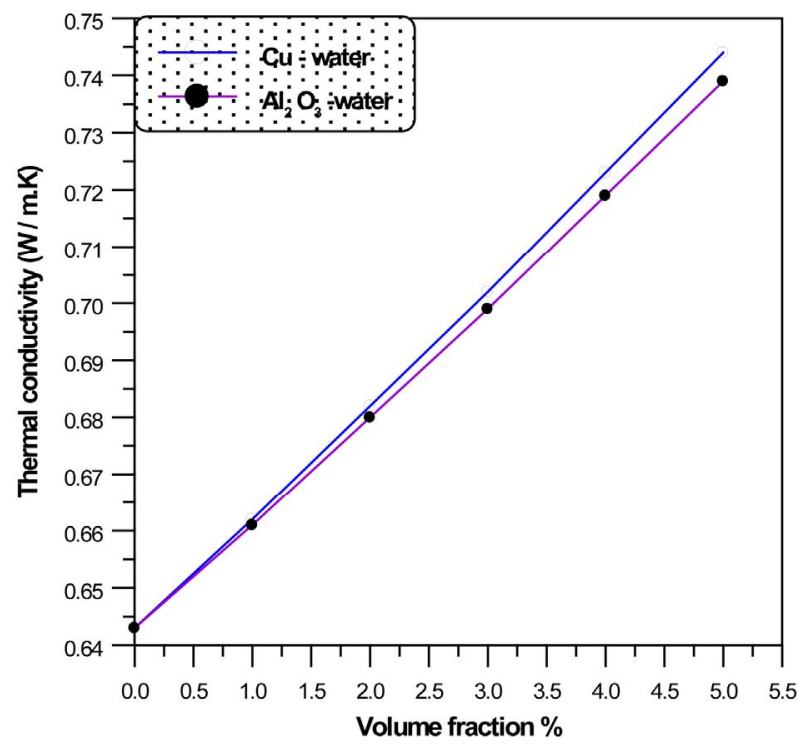

Figure 6. Variation of effectiveness with volume Fraction for two nanofluids at $\mathrm{Vi}=1 \mathrm{~m} / \mathrm{s}$.

nanofluids ( $\mathrm{Cu}$-water) and $\left(\mathrm{Al}_{2} \mathrm{O}_{3}\right.$-water) at inlet velocity 1 $\mathrm{m} / \mathrm{s}$. From this figure it can be seen that, the effectiveness for the two nanofluids increased with increase the solid particles in the nanofluid. The increase of effectiveness with increase volume fraction is due to increase of thermal conductivity of nanofluids. Also the increasing in effectiveness in case of $\mathrm{Cu}$-water is larger than that for $\mathrm{Al}_{2} \mathrm{O}_{3}$-water which is due to the higher thermal conductivity of $\mathrm{Cu}$-water than $\mathrm{Al}_{2} \mathrm{O}_{3}$-water. The observed modification in effectiveness results from using of the two mentioned nanofluids compared with that for pure water is $9.86 \%$ for $\mathrm{Cu}$-water and $5.04 \%$ for $\mathrm{Al}_{2} \mathrm{O}_{3}$-water at inlet velocity $1 \mathrm{~m} / \mathrm{s}$ and volume fraction $5 \%$.

Figure 7 represents the variation of pressure drop across heat exchanger with volume fraction for the two nanofluids used. From this figure the pressure drop increased with increase volume fraction for nanofluids which is due to increase its viscosity. Also there is a small difference between pressure drop in $\mathrm{Cu}$-water and $\mathrm{Al}_{2} \mathrm{O}_{3}$ water nanofluids which is due to the difference in density and viscosity between them.

The percentage increase in pressure drop associated with using nanofluids compared with pure water is $6.28 \%$ for $\mathrm{Cu}$-water and $6.19 \%$ for $\mathrm{Al}_{2} \mathrm{O}_{3}$-water at volume fraction $5 \%$ for inlet velocity $1 \mathrm{~m} / \mathrm{s}$.

Variation of performance index $(\eta)$ with volume fraction for two nanofluids at $\mathrm{Vi}=1 \mathrm{~m} / \mathrm{s}$ is illustrated in Figure 8. From this figure one can see that, the performance index for two nanofluids increased with increase the volume fraction. For $\mathrm{Cu}$-water nanofluid the increasing in performance index continue for all range of volume fraction chosen while for $\mathrm{Al}_{2} \mathrm{O}_{3}$-water the performance index reach a certain maximum value and then decreased. This is due to the increasing in effectiveness for $\mathrm{Cu}$-water as a result of increase the thermal conductivity is larger than the increment in pressure drop due to increase in viscosity for all range of selected volume fractions. While in case of $\mathrm{Al}_{2} \mathrm{O}_{3}$-water this increment occurred for small range of volume fractions and for remaining range the effect of the increasing in pressure drop become larger than that of increasing in the effectiveness which leads to decrease the performance index.

The maximum percentage in enhancement of the performance index results from using nanofluids compared with pure water is $4.84 \%$ for $\mathrm{Cu}$-water at volume fraction $5 \%$ and inlet velocity $1 \mathrm{~m} / \mathrm{s}$ and $1.45 \%$ for $\mathrm{Al}_{2} \mathrm{O}_{3}$-water at volume fraction $1 \%$ and inlet velocity $1 \mathrm{~m} / \mathrm{s}$.

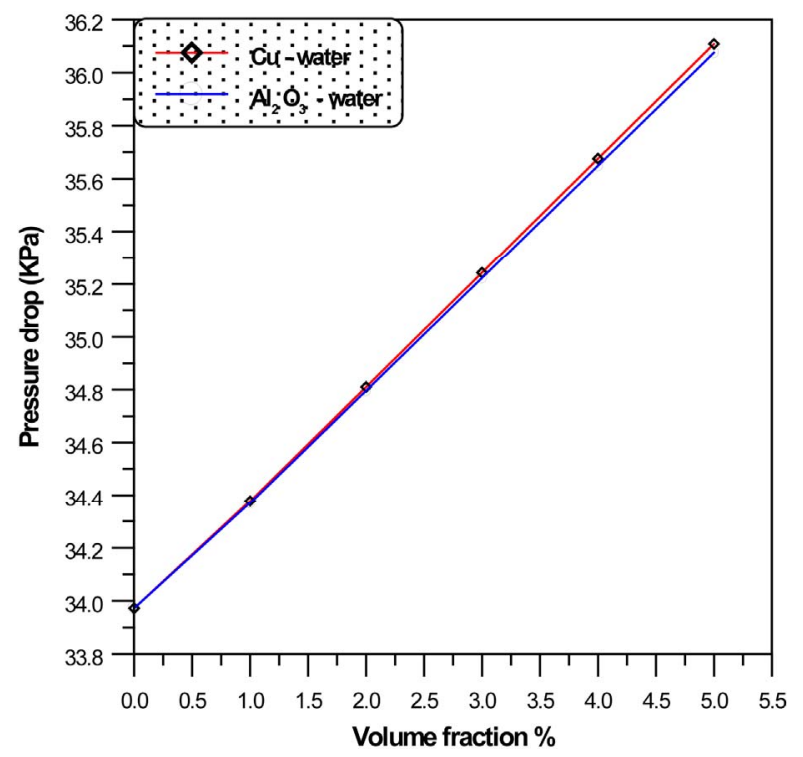

Figure 7. Variation of pressure drop with volume fraction for two nanofluids at $\mathrm{Vi}=1 \mathrm{~m} / \mathrm{s}$.

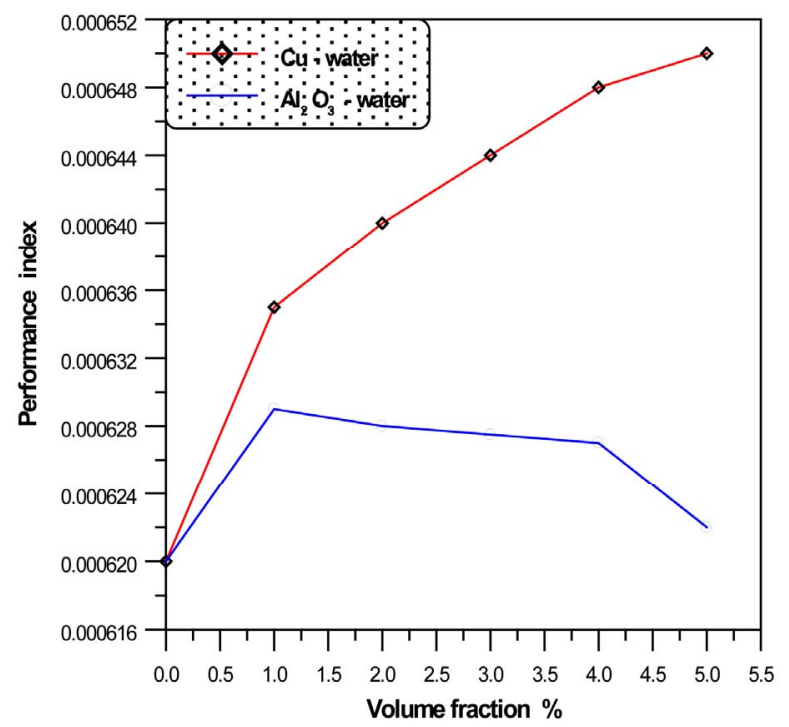

Figure 8. Variation of performance index with volume fraction for two nanofluids at $\mathrm{Vi}=1 \mathrm{~m} / \mathrm{s}$. 
Figure 9 illustrates the variation of heat transfer rate with the nanofluid volume fractions for two types of nanofluids. It's clear that the heat exchanged between two fluids increased with increasing of volume fraction. Also the heat transfer rate when using $\mathrm{Cu}$-water is larger thanthat for $\mathrm{Al}_{2} \mathrm{O}_{3}$-water because $\mathrm{Cu}$-water has higher thermal conductivity than $\mathrm{Al}_{2} \mathrm{O}_{3}$-water.

Variation of heat transfer rate over pumping power ratio (q/P.P) with volume fraction for two nanofluids at $\mathrm{Vi}=1 \mathrm{~m} / \mathrm{s}$ is shown in Figure 10. From this figure (q/P.P) ratio is increase with increase of volume fraction and has similar trend as for performance index shown in Figure 8. The maximum modification in $(\mathrm{q} / \mathrm{P} . \mathrm{P})$ compared

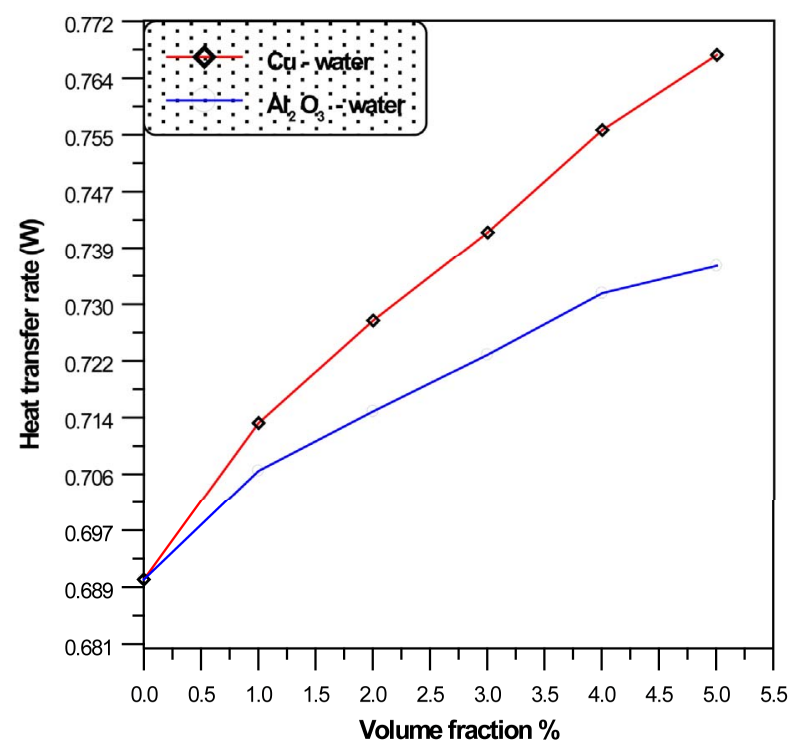

Figure 9. Variation of heat transfer rate with volume fraction for two nanofluids at $\mathrm{Vi}=1 \mathrm{~m} / \mathrm{s}$.

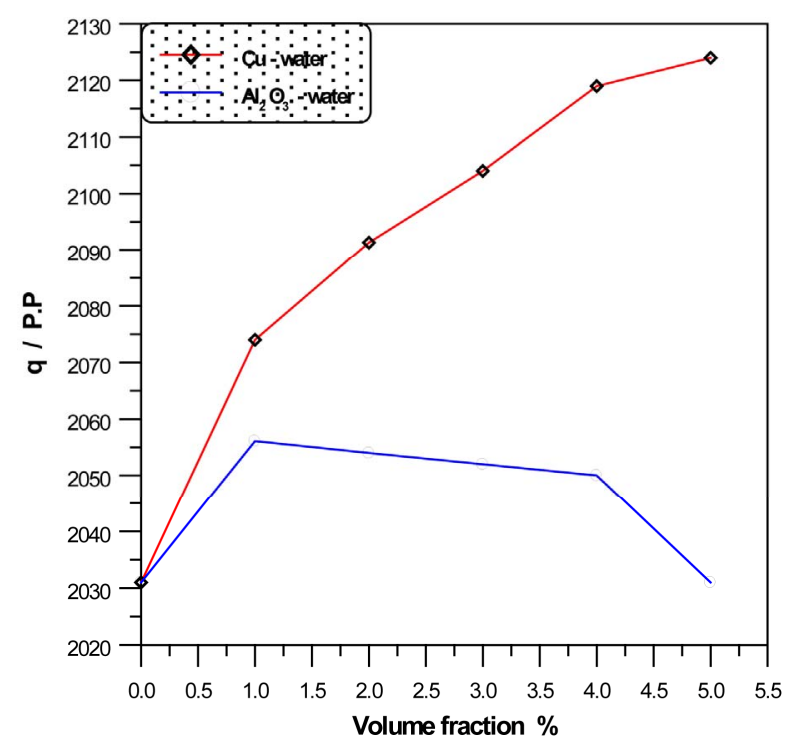

Figure 10. Variation of heat transfer rate over pumping power with volume fraction at $\mathrm{Vi}=1 \mathrm{~m} / \mathrm{s}$. with pure water is $4.57 \%$ for $\mathrm{Cu}$-water at volume fraction $5 \%$ and $\mathrm{Vi}=1 \mathrm{~m} / \mathrm{s}$ and $1.23 \%$ for $\mathrm{Al}_{2} \mathrm{O}_{3}$-water at volume fraction $1 \%$ and $\mathrm{Vi}=1 \mathrm{~m} / \mathrm{s}$.

Figure 11 shows the variation of effectiveness with inlet fluid velocity for different values of volume fraction. ( $c=0$ refer to pure water). From this figure it can be seen that the effectiveness decreased with increase of velocity. Also the large difference between different cases of volume fractions is occurred in low values of velocities and this difference is decreased with increase of fluid velocity. This is due to the effect of using nanofluids which appear in low flow rate while in high flow rate the flow is dominated by volume flow rate and the effect of sold particles on the developing of boundary layer.

Figure 12 shows the variation of performance index with inlet velocity for different values of volume fraction. From this figure the performance index decreased with increase inlet velocity. Also it can be seen that the difference between different cases is larger in low velocities and this difference decreases with increase of velocity due to decreasing of the effect of nanofluid in high velocity flow and the flow become dominated by flow rate.

Figure 13 shows the variation of overall heat transfer coefficient along CFMCHE for different values of volume fractions. From this figure one can observes that the difference between different cases is larger in the nanofluid inlet side i.e. at the entrance region which means that existence of nanoparticles in a nanofluid affect the developing of boundary layer. Also it can be seen that the overall heat transfer coefficient is variable along heat exchanger due to the effect of entrance region and exist of axial conduction.

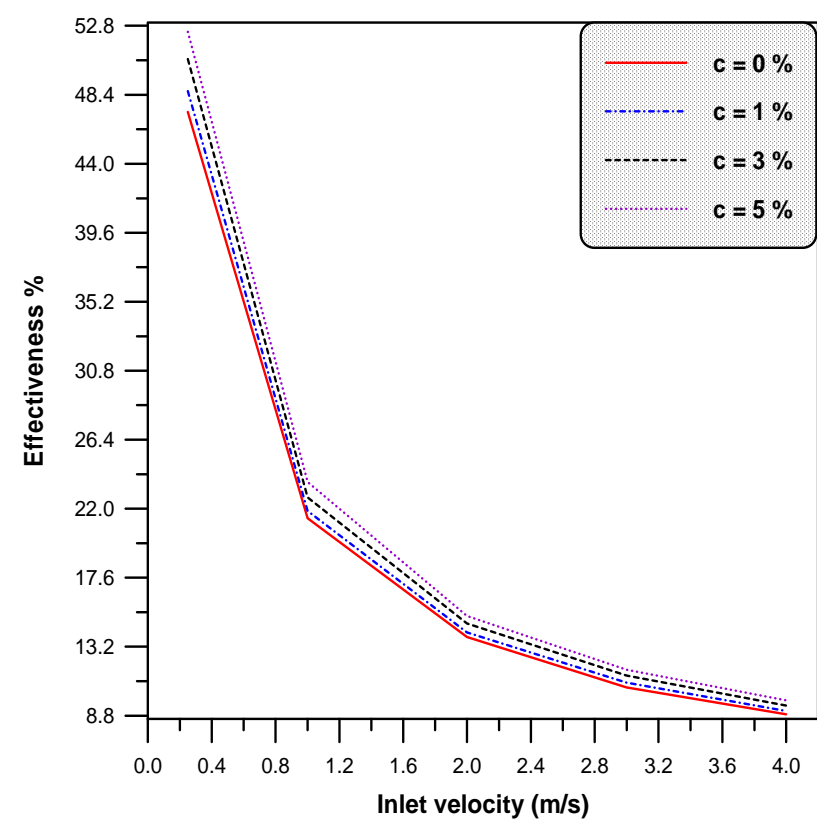

Figure 11. Variation of effectiveness with inlet velocity for different volume fractions for (Cu-water). 


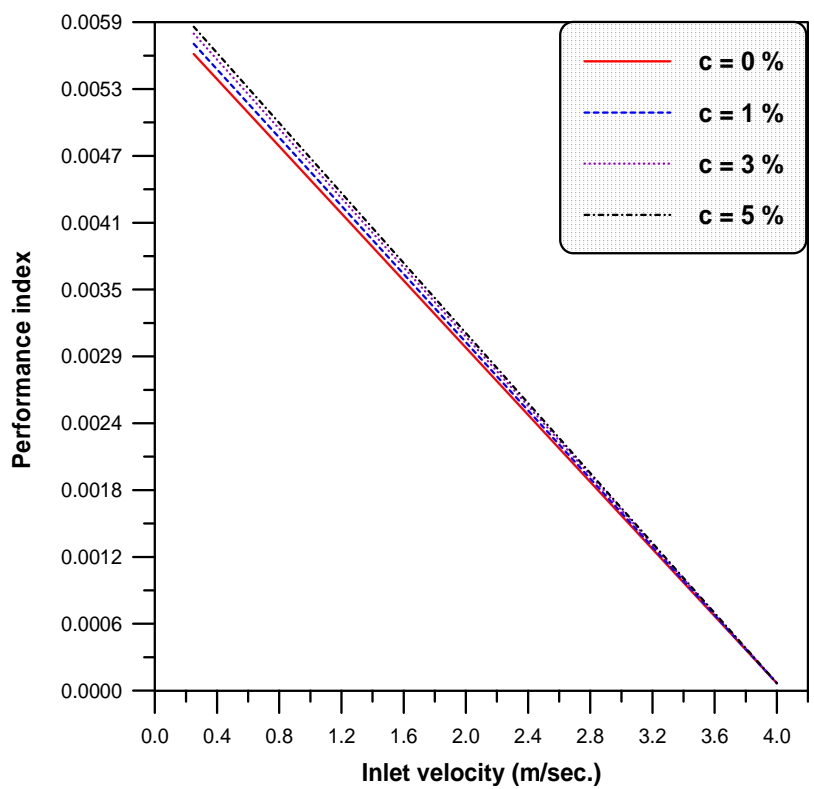

Figure 12. Variation of performance index with inlet velocity for different volume fractions for $\mathrm{Cu}$-water.

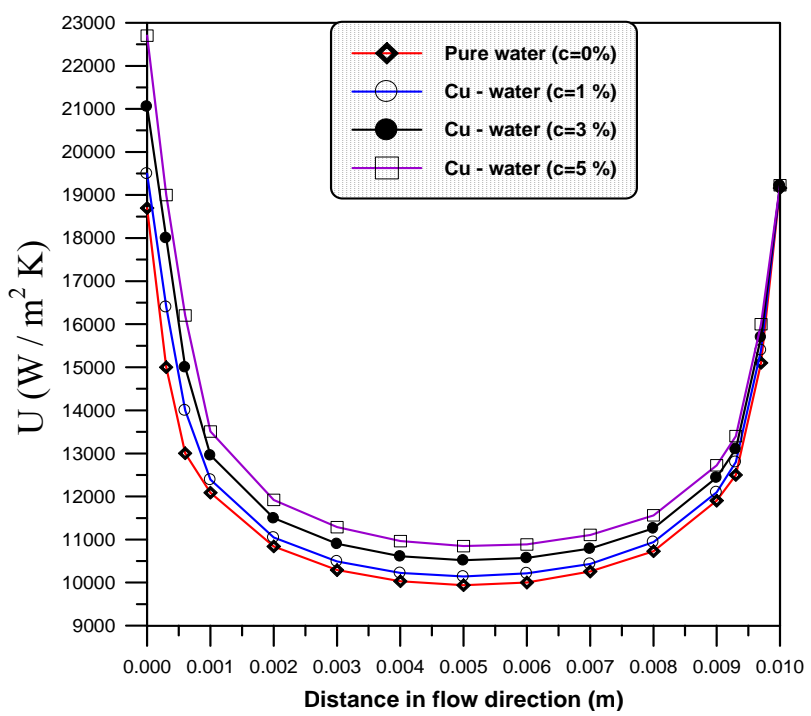

Figure 13. Variation of overall heat transfer coefficient along $\mathrm{H} . \mathrm{E}$ for different volume fractions $(\mathrm{Vi}=1 \mathrm{~m} / \mathrm{s})$.

\section{Conclusions}

In this paper a numerical investigation is made to study the effect of using nanofluids as cooling medium on the performance of counter flow microchannel heat exchanger. From the results it can be concluded that:

1) Using of nanofluids lead to increase the effectiveness and cooling performance of a CFMCHE;

2) There is no extra increase in pressure drop across CFMCHE associated with using of nanofluid as a coolant due to ultra fine particles and small volume fractions;

3) The effect of nanofluids is larger for low velocities while in flow with high velocities this effect is small because the flow will be dominated by the flow rate;

4) The effect of nanofluids is high in the entrance region due to the effect of solid particles on the developing of boundary layer;

5) The enhancement in thermal performance of CFM CHE increases with using material with high thermal conductivity.

\section{REFERENCES}

[1] D. B. Tuckerman and R. F. W. Pease, "High-Performance Heat Sinking for VLSI," IEEE Electron Device Letters, Vol. 2, No. 5, 1981, pp. 126-129. doi:10.1109/EDL.1981.25367

[2] X. W. Wang, X. F. Xu and S. U. S. Choi, "Thermal Conductivity of Nanoparticle-Fluid Mixture," Journal of Thermophysics and Heat Transfer, Vol. 13, No. 4, 1999, pp. 474-480.

[3] S. Lee, S. U. S. Choi, S. Li and J. A. Estman, "Measuring Thermal Conductivity of Fluids Containing Oxide Nanoparticles," Journal of Heat Transfer, Vol. 121, No. 2, 1999, pp. 280-289. doi:10.1115/1.2825978

[4] B.-X. Wang, L.-P. Zhou and X.-F. Peng, "A Fractal Model for Predicting the Effective Thermal Conductivity of Liquid with Suspension of Nanoparticles," International Journal of Heat and Mass Transfer, Vol. 46, No. 14, 2003, pp. 2665-2672. doi:10.1016/S0017-9310(03)00016-4

[5] J. Koo and C. Kleinstreuer, "A New Thermal Conductivity Model for Nanofluids," Journal of Nanoparticle Research, Vol. 6, No. 6, 2004, pp. 577-588. doi:10.1007/s11051-004-3170-5

[6] Q. Li and Y. M. Xuan, "Convective Heat Transfer and Flow Characteristics of Cu-Water Nanofluid," Science in China Series E: Technological Sciences, Vol. 45, No. 4, 2002, pp. 408-416.

[7] Y. M. Xuan and Q. Li, "Investigation on Convective Heat Transfer and Flow Features of Nanofluids," Journal of Heat Transfer, Vol. 125, No. 1, 2003, pp. 151-155. doi:10.1115/1.1532008

[8] B. C. Pak and Y. I. Cho, "Hydrodynamic and Heat Transfer Study of Dispersed Fluids with Submicron Metallic Oxide Particles," Experimental Heat Transfer, Vol. 11, No. 2, 1998, pp. 151-170. doi:10.1080/08916159808946559

[9] D. S. Wen and Y. L. Ding, "Experimental Investigation into Convective Heat Transfer of Nanofluids at the Entrance Region under Laminar Flow Conditions," International Journal of Heat and Mass Transfer, Vol. 47, No. 24, 2004, pp. 5181-5188. doi:10.1016/j.ijheatmasstransfer.2004.07.012

[10] S. P. Jang and S. U. S. Choi, "Cooling Performance of a Microchannel Heat Sink with Nanofluids," Applied Thermal Engineering, Vol. 26, No. 17-18, 2006, pp. 2457-2463. doi:10.1016/j.applthermaleng.2006.02.036

[11] T.-H. Tsai and R. Chein, "Performance Analysis of Nanofluid-Cooled Microchannel Heat Sinks," International Journal of Heat and Fluid Flow, Vol. 28, No. 5, 2007, pp. 1013-1026. doi:10.1016/i.ijheatfluidflow.2007.01.007

[12] J. Lee and I. Mudawar, "Assessment of the Effectiveness 
of Nanofluids for Single-Phase and Two-Phase Heat Transfer in Micro-Channels," International Journal of Heat and Mass Transfer, Vol. 50, No. 3-4, 2007, pp. 452-463. doi:10.1016/i.ijheatmasstransfer.2006.08.001

[13] M. I. Hasan, A. A. Rageb, M. Yaghoubi and H. Homayony, "Influence of Channel Geometry on the Performance of Counter Flow Microchannel Heat Exchanger," International Journal of Thermal Sciences, Vol. 48, No. 8, 2009, pp. 1607-1618. doi:10.1016/j.ijthermalsci.2009.01.004

[14] M. I. Hasan, "Numerical Investigation of Counter Flow Microchannel Heat Exchanger with MEPCM Suspension," Applied Thermal Engineering, Vol. 31, No. 6-7, 2011, pp. 1068-1075. doi:10.1016/j.applthermaleng.2010.11.032

[15] R. Chein and J. Chuang, "Experimental Microchannel Heat

\section{Nomenclature}

C Volume fraction of solid particle

$\mathrm{C}_{\mathrm{p}} \quad$ Specific heat $(\mathrm{J} \backslash \mathrm{kg} \cdot \mathrm{K})$

$\mathrm{K}$ Thermal conductivity $(\mathrm{W} / \mathrm{m} \cdot \mathrm{K})$

$\mathrm{K}_{\mathrm{r}} \quad$ Thermal conductivity ratio $\mathrm{kf} / \mathrm{ks}$

$\dot{m} \quad$ Mass flow rate $(\mathrm{kg} / \mathrm{s})$

$\mathrm{P} \quad$ Total pressure $(\mathrm{Pa})$

$\mathrm{P}_{\mathrm{r}} \quad$ Prandtl number $\left(\mu \mathrm{C}_{\mathrm{p}} / \mathrm{k}\right)$

q Heat transfer rate (W)

$\mathrm{q}_{\max } \quad$ Maximum heat transfer rate through the heat exchanger (W)

Re Reynolds number (uiDh $/ \gamma)$

T Temperature (K)

$\mathrm{T} \quad$ Separating wall thickness (m)

U Fluid $\mathrm{x}$-component velocity $(\mathrm{m} / \mathrm{s})$

V Fluid y-component velocity $(\mathrm{m} / \mathrm{s})$

W Fluid z-component velocity $(\mathrm{m} / \mathrm{s})$

W Square channel width (m)

$\mathrm{x} \quad$ Axial coordinate $(\mathrm{m})$
Sink Performance Studies Using Nanofluids," International Journal of Thermal Sciences, Vol. 46, No. 1, 2007, pp. 57-66. doi:10.1016/j.ijthermalsci.2006.03.009

[16] S. V. Patankar, "Numerical Heat Transfer and Fluid Flow," Hemisphere Publishing Corporation, Washington DC, New York, London, 1980.

[17] F. P. Incropera and D. P. Dewitt, "Fundamentals of heat and mass transfer," 4th Edition, John Wiley and Sons, Hoboken, 1996.

[18] Q. Weilin and M. Issam, "Thermal Design Methodology for High-Heat-Flux Single Phase and Two Phase Microchannel Heat Sinks," IEEE Transactions on Components and Packaging Technologies, Vol. 26, No. 3, 2003, pp. 598-609. doi:10.1109/TCAPT.2003.817652 y Vertical coordinate (m)

$\mathrm{z} \quad$ Horizontal coordinate $(\mathrm{m})$

$\Delta \mathrm{P} \quad$ Pressure drop across heat exchanger $(\mathrm{Pa})$

Greek Symbols

P Density $\left(\mathrm{kg} / \mathrm{m}^{3}\right)$

$\mu \quad$ Dynamic viscosity $\left(\mathrm{m}^{2} / \mathrm{s}\right)$

$\varepsilon \quad$ Heat exchanger effectiveness

Subscripts

h Hot fluid

c Cold fluid

i Inlet

o Outlet

$\min \quad$ Minimum value

max Maximum value

s Solid

f Fluid

W Wall 